\title{
The most preferable working point investigation of the serial-serial system of wireless energy transfer in term of high efficiency
}

\author{
Spanik P., Frivaldsky M., Piri M., Jaros V., Kozacek. B. \\ Department of Mechatronics and Electronics \\ Faculty of Electrical Engineering, University of Zilina \\ Zilina, Slovakia \\ marek.piri@fel.uniza.sk
}

\begin{abstract}
The efficiency is the most important factor which is to maximazed during the wireless energy transfer system development but also at the other electronics devices. Therefore this artice deals with the most suitable working point analysis of such a system. The center of the article contains the experimental measurements on the existing sample and consequently comparison with the results from the simulation analysis
\end{abstract}

Keywords-component; formatting; style; styling; insert (key words)

\section{INTRODUCTION (HEADING 1)}

The market for electric cars is small. The market for these systems with contactless charging (wireless energy transfer WET) is even smaller.

A very important parameter of the WET system is the efficiency of the entire charging system. The efficiency should be as large as possible and should correspond to the efficiency value of contact charging systems. Current cable charging systems achieve $97.5 \%$ efficiency at $240 \mathrm{~V}$ supply voltage and $95 \%$ at $120 \mathrm{~V}$ supply voltage. Additional specific features of WET system should be flexible adaptation of distance for power transfer and misalignment of transmitter and receiver platform. The reason is that each electric vehicle model has a different ride height and just as it is not always possible to park the vehicle completely symmetrically so that the receiving platform is located perfectly symmetrically with transmitting platform. All of these demands can be influenced via several parameters. The parameters are a way of compensation circuit wiring, the resonant frequency, the switching frequency, the geometric shape of coils, the parasitic resistance of coils, the coils inductance and the resulting mutual inductance. Mentioned variables are the most important parameters that need to be in the process of system development and optimization in focus.

Irrespective of the application area, can be said that the main common features of these systems should be:

- The high efficiency of contactless energy transfer system $(>85 \%)$.
- Achievement of the middle transfer distances (up to $1 \mathrm{~m}$ ), while maintaining high efficiency (> 85\%).

- Transfer of power at middle levels (from 1 $\mathrm{kW}-3 \mathrm{~kW})$.

In this article we will focus on the analysis of WET system in circuitry with serial compensation of series resonant circuit. Main emphasis will be on investigation of the transfer characteristics in terms of the size of the transferred power, efficiency, and transfer distance.

\section{WET SYSTEM WITH SERIAL COMPENSATION}

Serial compensation of primary and secondary side (Fig. 1.) securing the ideal characteristic properties for this system. To the main properties belongs the voltage gain, efficiency and the shape of the transfer characteristic. The simulation analysis proved as that the remaining basic topological solutions of this system are not ideal because they are characteristics thereby that with increasing the distance between the coils the efficiency of the system sharply falls. Theirs characteristic of efficiency and transferred energy dependency is comparable with inductive WET system.

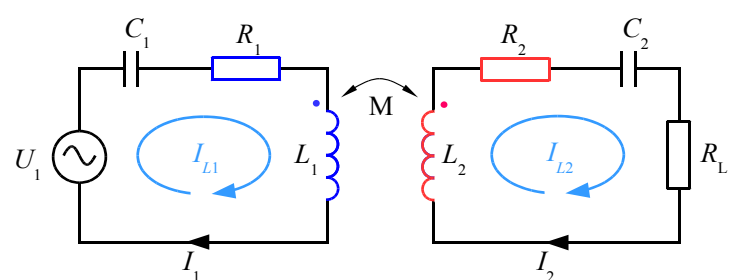

Figure 1. Equivalent circuit of WET with series-series resonant compensation

The external capacitors $C_{1}$ and $C_{2}$ are connected to the primary and the secondary coil in series. Therefore the resonant tank acts as a band-pass filter with relatively good selectivity. Considering the equivalent circuit (Fig. 1), it is possible to assemble a system of two linear equations with two unknowns (1). 


$$
\left[\begin{array}{c}
\dot{U}_{1} \\
0
\end{array}\right]=\left[\begin{array}{cc}
R_{1}+j\left(\omega L_{1}-\frac{1}{\omega C_{1}}\right) & -j \omega M \\
-j \omega M & R_{2}+R_{L}+j\left(\omega L_{2}-\frac{1}{\omega C_{2}}\right)
\end{array}\right]\left[\begin{array}{c}
\dot{I}_{L 1} \\
\dot{I}_{L 2}
\end{array}\right](1)
$$

The parameters $\mathrm{R} 1$ and $\mathrm{R} 2$ represents the $\mathrm{DC}$ resistance of the wire from which is mounted the coils L1 and L2. Next the parameter M reprezents the mutual iductance, which is created between the coils L1 and L2 close together.

The solution of this system results in the formula for the size of the output power (2) and the efficiency (3) depending on the distance between the transmitting and the receiving portion of the system (size of mutual inductance). The important parameter in term of the control is the angle of the phase shift between the primary voltage and current (4).

$$
\begin{gathered}
P_{\text {OUT }}=R_{L}\left|\dot{I}_{2}\right|^{2}=R_{L} \cdot\left|\frac{-j \omega M}{\left(R_{1}+j \omega L_{1}\right) \cdot\left(R_{2}+R_{L}+j \omega L_{2}\right)+(\omega M)^{2}} \dot{U}_{1}\right|^{2} \\
\eta=\frac{P_{\text {OUT }}}{P_{I N}} \\
\varphi=\operatorname{arctg} \frac{X_{L}-X_{C}}{R}
\end{gathered}
$$

By mentioned relations it is possible to graphically interpret the transfer characteristic of the WET system.

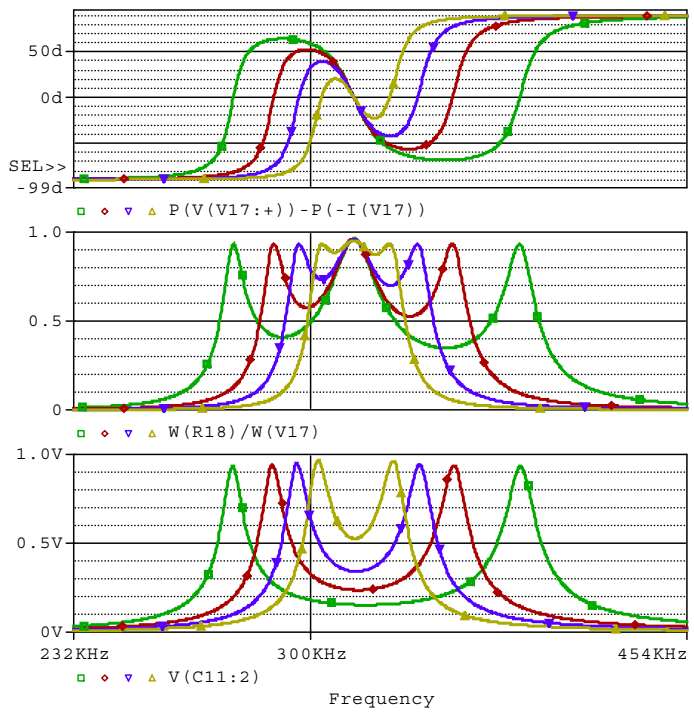

Figure 2. Equivalent Transfer characteristic of S-S compensated WET circuit for various mutual inductances (i. e. various distances between coils): phase shift bedtween Uin and Iin characteristic (upper graph), efficiency characteristic (middle graph) and voltage transfer (lower graph)

For optimum operation of the charging of electromobility applications should be valid this condition:

- Maximum efficiency at the same time with maximum performance
From mentioned characteristics the optimal working points can be defined. The most suitable working points, as it can be seen from the graph, are the lateral maxima of the efficiency curve. This maxima or resonant frequencies arise from the influence of the mutual inductance and amount of the load on the secondary receiver coil.

\section{OPTIMAL WORKING AREAS (FREQUENCIES) DEFINITION FOR WET SYSTEM.}

To define the most suitable working area, the simulation analysis in the frequency domain in the OrCad - Pspice. Values of single components are as follows: the transferring and receiving coil inductance is $127,8 \mathrm{uH}$, the value of the compensation capacitors is $2 \mathrm{nF}$ and the value of the load is $12 \mathrm{ohm}$. Value of resonance frequency is equal to $315 \mathrm{kHz}$.

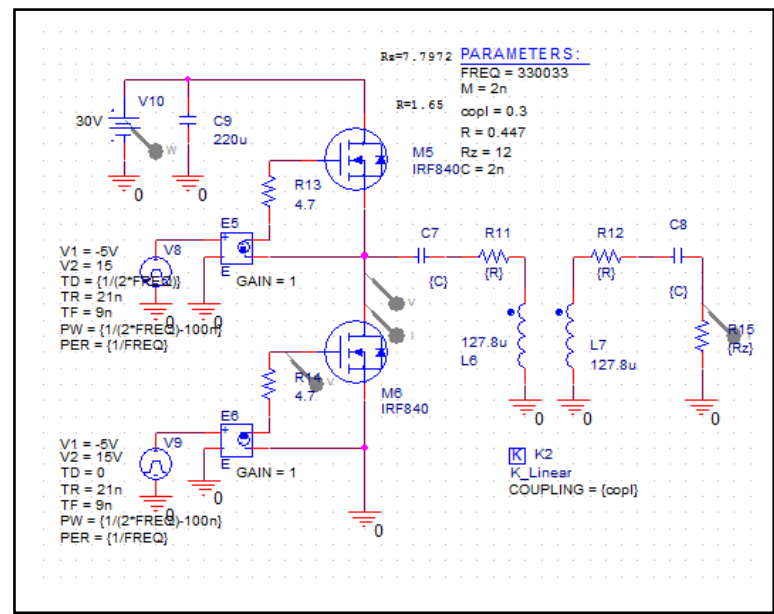

Figure 3. Scheme of the WET system intended for analysis in the time straight

Graph (Fig. 4.) illustrates the phase shift, efficiency and voltage transfer dependency on frequency by the various distances or various coupling coefficient , $\mathrm{K}^{*}$. The lateral maxima of frequencies were found out by the system frequency analysis from the phase shift graph. In these working points (frequencies), the phase shift between the input current and the voltage is equal to ,0"degrees. That means that current and the voltage is in the phase. The circuit is supplied with harmonic voltage $1 \mathrm{Vpp}$.

- Green curve: $\mathrm{k}=0,3076 \mathrm{~d}=10 \mathrm{~cm}$

- Red curve: $\quad \mathrm{k}=0,1995 \mathrm{~d}=15 \mathrm{~cm}$

- Blue curve: $\quad \mathrm{k}=0,1382 \mathrm{~d}=20 \mathrm{~cm}$

- Yellow curve: $\mathrm{k}=0,0891 \mathrm{~d}=25 \mathrm{~cm}$ 


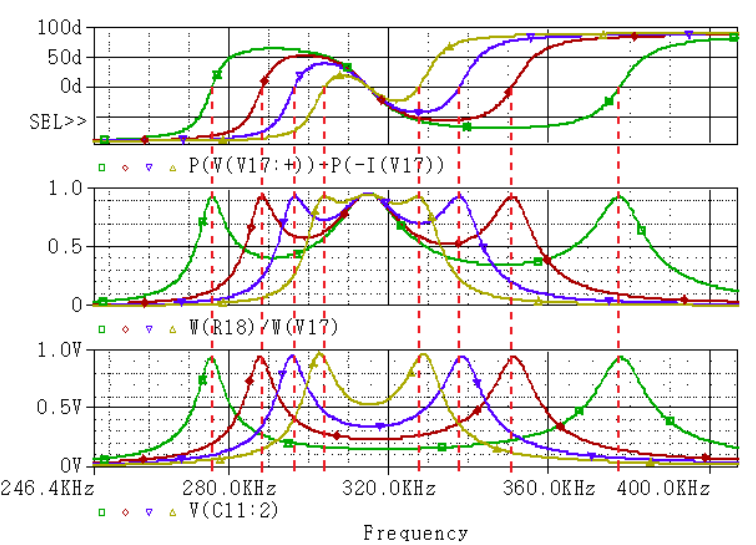

Figure 4. Phase shift, efficiency and voltage gain frequency curves with demarcated lateral maxima, which are hypotetic the most preferable working points.

Founded frequencies with the various vales of coupling coefficient are further used for the circuit time analysis. From the curves of power losses of transistor it is determined which working points are the most suitable in term of efficiency.

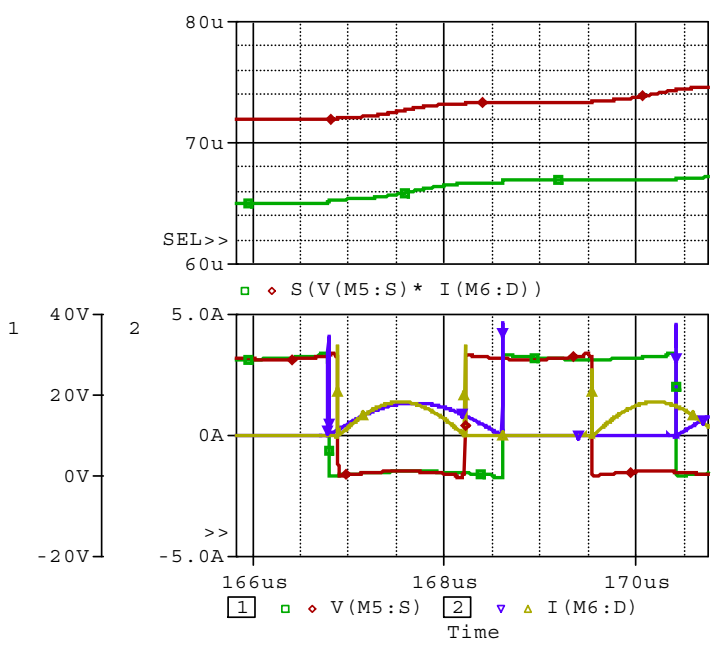

Figure 5. Power loss curves on the tranzistor at the $\mathrm{k}=0,3076$, distance of the coils $\mathrm{d}=10 \mathrm{~cm}, \mathrm{fr}=275827 \mathrm{~Hz}$ and $377540 \mathrm{~Hz}$ $\mathrm{pd}=1,856 \mathrm{u} \mathrm{ph}=1,407 \mathrm{u} \mathrm{Ed}=0,5144 \mathrm{~J} \mathrm{Eh}=0,5312 \mathrm{~J}$.
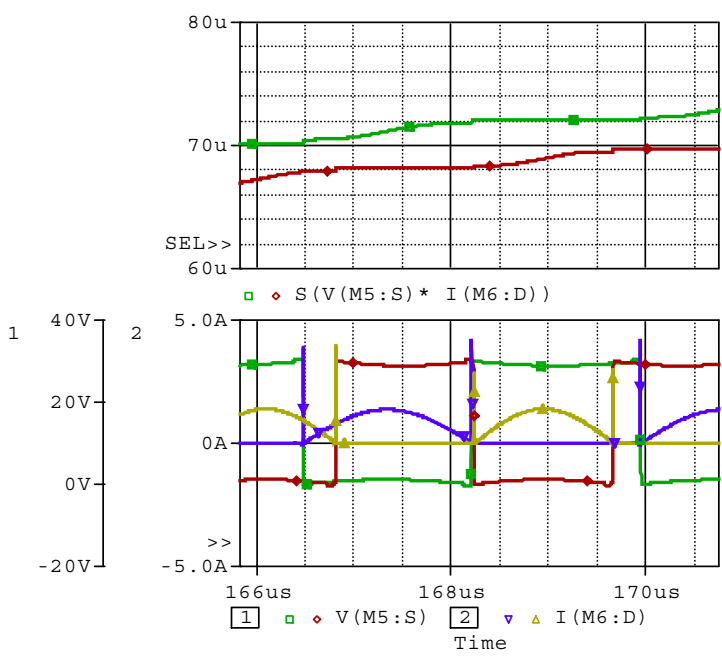

Figure 6. Power loss curves on the tranzistor at the $\mathrm{k}=0,199$ distance of the coils $\mathrm{d}=15 \mathrm{~cm}, \mathrm{fr}=288359 \mathrm{~Hz}$ and $350738 \mathrm{~Hz}$ $\mathrm{pd}=1,878 \mathrm{ph}=1,523 \mathrm{Ed}=0,5415 \mathrm{~J} \mathrm{Eh}=0,5342 \mathrm{~J}$.
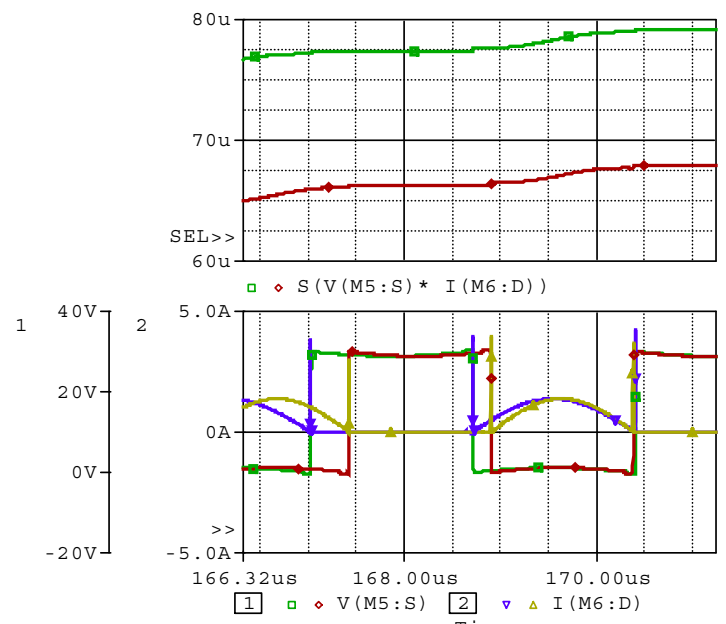

Figure 7. Power loss curves on the tranzistor at the $\mathrm{k}=0,1382$, distance of the coils $\mathrm{d}=20 \mathrm{~cm}, \mathrm{fr}=296394 \mathrm{~Hz}$ and $337516 \mathrm{~Hz}$ $\mathrm{pd}=1,829 \mathrm{ph}=1,605 \mathrm{Ed}=0,5425 \mathrm{~J} \mathrm{Eh}=0,5417 \mathrm{~J}$
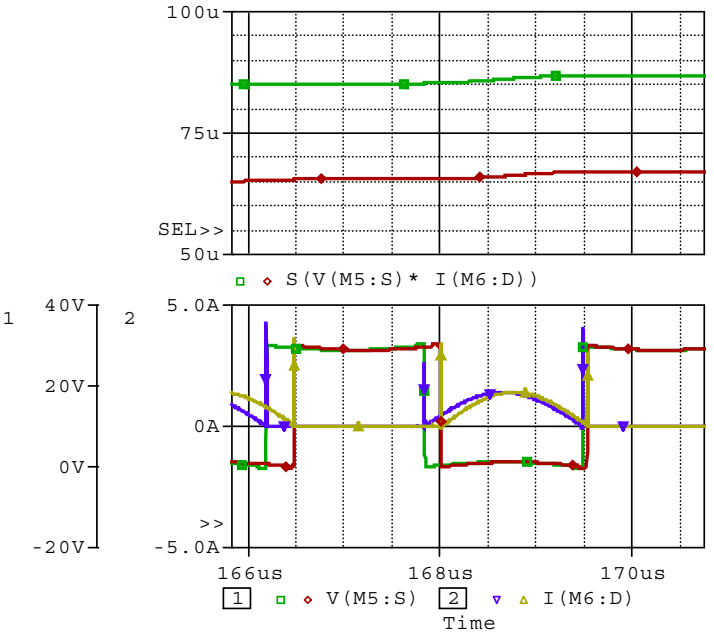

Figure 8. Power loss curves on the tranzistor at the $k=0,0891$, distance of the coils $\mathrm{d}=25 \mathrm{~cm}, \mathrm{fr}=303900 \mathrm{~Hz}$ and $327406 \mathrm{~Hz}$ $\mathrm{pd}=1,513 \mathrm{ph}=1,436 \mathrm{Ed}=0,4598 \mathrm{~J} \mathrm{Eh}=0,47 \mathrm{~J}$. 
From the curves shown above, it can be seen that the whole power losses on the transistor working on lateral maxima of the efficiency characteristic are approximately identical. In the case of increasing distance it can be observed, that it is works better on that maximum characteristic which has higher frequency.

\section{EXPERIMENTAL VERIFICATION OF SIMULATED RESULTS}

Before the experimental verification, the physical sample was set up, which is equivalent to the simulation model of WET system in OrCad. Consequently, from the frequency analysis the frequencies, in which there are the efficiency maxima by the various values of the coupling coefficient, were found out.

TABLE I. FREQUENCIES OF THE LATERAL MAXIMA BY THE VARIOUS VALUES OF THE COUPLING COEFICIENT INTENDED FROM FREQUENCY ANANLYSIS OF WET SYSTEM

\begin{tabular}{|c|c|c|}
\hline $\begin{array}{c}\text { distance } \\
\text { [cm] }\end{array}$ & $\begin{array}{c}\text { Frequency of } \\
\text { lower } \\
\text { maximum[kHz] }\end{array}$ & $\begin{array}{c}\text { Frequency of upper } \\
\text { maximum [kHz] }\end{array}$ \\
\hline 5 & 249,455 & 494,939 \\
\hline 10 & 275,827 & 377,54 \\
\hline 15 & 288,359 & 350,738 \\
\hline 20 & 296,394 & 337,516 \\
\hline 25 & 303,9 & 327,406 \\
\hline 30 & 309,348 & 320,969 \\
\hline
\end{tabular}

These frequencies were then used by the analysis of the system in the time domain together with appertaining values of coupling coefficient. The results of this analysis are shown in the table (Tab. 2.).

TABLE II. THE RESUTS OBTAINED FROM SIMULATION IN TIME DOMAIN DESIGNED SYSTEM OF WET BY THE OPTIMAL WORKING POINTS OPERATION.

\begin{tabular}{|c|c|c|c|c|}
\hline $\mathbf{d}[\mathbf{c m}]$ & $\mathbf{P}_{\text {outfd }}[\mathbf{W}]$ & $\mathbf{P}_{\text {outf }}[\mathbf{W}]$ & $\boldsymbol{\eta f d}[\mathbf{\%}]$ & $\boldsymbol{\eta f h}[\mathbf{\%}]$ \\
\hline 5 & 10,4 & 11,39 & 82,8 & 84,6 \\
\hline 10 & 10,39 & 11,25 & 83 & 84,3 \\
\hline 15 & 10,4 & 11,2 & 83,4 & 84 \\
\hline 20 & 10,99 & 11,2 & 83,2 & 83,8 \\
\hline 25 & 11 & 11,29 & 84,05 & 84,3 \\
\hline 30 & 11,15 & 11,37 & 83,2 & 83,5 \\
\hline
\end{tabular}

The calculated and simulated results were verified on proposed functional prototype of WET system.
TABLE III. THE RESUTS OBTAINED FROM MEASUREMENT ON PHYSICAL SAMPLE OF WET SYSTEM BY THE OPTIMAL WORKING POINTS OPERATION..

\begin{tabular}{|c|c|c|c|c|c|c|}
\hline $\mathbf{d}[\mathbf{c m}]$ & $\begin{array}{c}\mathbf{P}_{\text {outfd }} \\
{[\mathbf{W}]}\end{array}$ & $\begin{array}{c}\mathbf{P}_{\text {outfh }} \\
{[\mathbf{W}]}\end{array}$ & $\begin{array}{c}\mathbf{\eta f d} \\
{[\%]}\end{array}$ & $\begin{array}{c}\mathbf{\eta} \mathbf{\%} \\
{[\%]}\end{array}$ & $\begin{array}{c}\mathbf{f d} \\
{[\mathbf{k H z}]}\end{array}$ & $\begin{array}{c}\mathbf{f h} \\
{[\mathbf{k H z}]}\end{array}$ \\
\hline 5 & 15,35 & 12,075 & 82,75 & 83,88 & 254,5 & 479,42 \\
\hline 10 & 13,85 & 12,981 & 83,97 & 86,57 & 276,2 & 388,1 \\
\hline 15 & 13,1 & 12,54 & 85,32 & 87,11 & 289,8 & 355,6 \\
\hline 20 & 10,05 & 10,281 & 77,33 & 85,7 & 299,5 & 339,2 \\
\hline 25 & 11,45 & 14,248 & 84,84 & 83,575 & 305 & 333,1 \\
\hline 30 & 12,15 & 17,680 & 82,68 & 83,036 & 307,8 & 327,7 \\
\hline
\end{tabular}

\section{CONCLUSION}

When comparing the results of the efficiency and transferred power from (Tab. II) and (Tab. III), it can be pointed out that the results of measuring and simulation are relatively well corresponding. Inaccuracies which arise were probably caused by using another type of transistor in simulation analysis compared to real sample of inverter. The real sample of WET was supplied by development board EPC9003C which contains the synchronous inverter with GaN transistors EPC2010. These transistors have markedly lower resistance on opened state $\mathrm{R}_{\mathrm{DSon}}$, which could be one reason of inaccuracies between measuring and simulated results. Inaccuracy of working frequency could be caused mainly by inaccurate distance of coils on the experimental sample as well as by inaccurate calculation of coupling coefficient.

\section{ACKNOWLEDGMENT (Heading 5)}

The authors wish to thank to Slovak grant agency APVV for project no. APVV-0433-12 - Research and development of intelligent system for wireless energy transfer in electromobility application.

\section{REFERENCES}

[1] Kindl, V.; Kavalir, T.; Pechanek, R.; Skala, B.; Sobra, J., "Key construction aspects of resonant wireless low power transfer system," ELEKTRO, 2014 , vol., no., pp.303,306, 1920 May 2014

[2] Skala, B., Kindl, V.: Electromagnetic coil gun - construction and basic simulation, In: Mechatronics 2013, pp. 87 - 93, ISBN 978-3-319-02293-2, Springer International Publishing

[3] Hruska, K.; Kindl, V.; Pechanek, R., "Concept, design and coupled electro-thermal analysis of new hybrid drive vehicle for public transport," in Power Electronics and Motion Control Conference (EPE/PEMC), 2010 14th International, vol., no., pp.S4-5-S4-8, 6-8 Sept. 2010

[4] Brandstetter, P., Chlebis, P., Palacky, P.: Application of RBF network in rotor time constant adaptation, In: Elektronika IR elektrotechnika, Issue:7, pp.21-26, 2011.

[5] Grman, L., Hrasko, M., Kuchta, J.: Single phase PWM rectifier in traction application, In: Journal of electrical engineering-elektrotechnicky casopis, Vol: 62, Issue:4, pp. 206 - 212, August 2011

[6] Ferkova, Z., Franka, M., Kuchta, J.: Electromagnetic design of Ironless Permanent Magnet Synchronous Linear motor, In: International symposium on power electronics, electrical 
drives, automation and motion (SPEEDAM), Italy, June 1113, 2008, pp. 721-726.

[7] Kovacova, I., Kovac, D.: Inductive coupling of power converter's EMC, In: Acta polytechnica hungarica, Vol:6, Issue:2, pp. 41-53, 2009.

[8] Perdulak, J., Kovac, D., Kovacova, I., Ocilka, M., Gladyr, A., Mamchur, D., Zachepa, I., Vince, T., Molnár, J.: Effective utilization of photovoltaic energy using multiphase boost converter in compare with single phase boost converter, In: CSL Communications - Scientific letters of university of Zilina, Vol. 15, No.3, 2013, ISSN 1335-4205

[9] Chlebis P., Havel A., Vaculik P., Pfof Z.: Modern Instruments for increasing the Efficiency of the Energy Transfer in Electric Vehicles. In 14th International Power Electronics and Motion Control Conference (EPE-PEMC), Ohrid, Macedonia, 2010, pp. 89-93, ISBN 978-1-4244-7854-5

[10] P. Chlebis, P. Moravcik, P. Simonik: "Method of Direct Torque Control for Three-level Voltage Inverter." In 13th European Conference on Power Electronics and Applications (EPE 2009), Barcelona, Spain, 2009, Vols. 1-9, pp. 40514056, ISBN:978-1-4244-4432-8.

[11] Brandstetter, P.; Chlebis, P.; Simonik, P.: Active Power Filter with Soft Switching, In: INTERNATIONAL REVIEW OF ELECTRICAL ENGINEERING-IREE Vol: 5, Iss: 6 Pages: 2516-2526

[12] Dudrik, J., Bodor, M., Trip, N.D.: Operation analysis of soft switching PWM DC-DC converter with secondary snubber, In: CSL Communications - Scientific letters of university of Zilina, Vol. 15, No.3, 2013, ISSN 1335-4205
[13] Zaskalicky, P., Dobrucky, B., Prazenica, M.: Analysis and Modeling of Converter with PWM Output for Two-Phase Applications, In: Electronics and Electrical Engineering, Vol. 20, No. 1 (2014), Kaunas 2014, pp. 25-28, ISSN 1392-1215

[14] HOCK, O., DRGONA, P., PASKALA, M.: Simulation Model of Adjustable Arm Using Denavit-Hartenberg Parameters, In: 10th International Conference ELEKTRO 2014, Rajecke Teplice, Slovakia, 19-20 May, 2014, IEEE, pp. 176-179, Catalog number: CFP1448S-CDR, ISBN: 978-1-4799-37202 ,

[15] LASKODY, T., PRAZENICA, M., KASCAK, S.: Space Vector PWM for Two-Phase Four-Leg Matrix Converter, In: 10th International Conference ELEKTRO 2014, Rajecke Teplice, Slovakia, 19-20 May, 2014, IEEE, pp. 234-327, Catalog number: CFP1448S-CDR, ISBN: 978-1-4799-37202,

[16] HARGAS, L., KONIAR, D., HRIANKA, M., SIMONOVA, A., DURDIK, P., BANOVCIN, P.: Adjusting and Conditioning of High Speed Videosequences for Diagnostic Purposes in Medicine, In: 10th International Conference ELEKTRO 2014, Rajecke Teplice, Slovakia, 19-20 May, 2014, IEEE, pp. 548-552, Catalog number: CFP1448S-CDR, ISBN: 978-1-4799-3720-2,

[17] 740-741, August 1987 [Digests 9th Annual Conf. Magnetics Japan, p. 301, 1982].

[18] M. Young, The Technical Writer's Handbook. Mill Valley, CA: University Science, 1989. 